\title{
Mechanisms of Disease: the role of heat-shock protein 90 in genitourinary malignancy
}

\author{
Jean-Baptiste Lattouf, Ramaprasad Srinivasan, Peter A Pinto, W Marston Linehan and Leonard Neckers*
}

\section{SUMMARY}

Insight into the molecular biology of cancer has allowed the development of novel therapeutic strategies that target specific oncogenic pathways. Molecular therapeutic strategies are now part of the armamentarium available against urologic malignancy. Among the many targets of interest in urologic cancer, heat-shock protein 90 (HSP90) shows great promise. This molecule has a major role in prostate as well as in renal malignancy. In contrast to other targets, where cancer might escape inhibition via alternative pathways, HSP90 operates at multiple checkpoints in a cancer cell. Its inhibition could, therefore, prove more difficult for neoplastic cells to overcome. Inhibitors of HSP90, such as geldanamycin and its derivatives (17-allylamino-17-demethoxygeldanamycin and 17-dimethylaminoethylamino-17-demethoxygeldanamycin, known as 17AAG and 17DMAG, respectively) are available and have shown activity both in vivo and in vitro. 17AAG is currently being tested for efficacy in humans after having completed phase I trials, while 17DMAG is still in phase I evaluation. Phase II trials of HSP90 inhibitors in urologic malignancy are being conducted in kidney and advanced prostate cancer. Beyond monotherapy, HSP90 inhibitors might also prove to be beneficial in combination therapy with other chemotherapeutic agents in advanced disease. Studies being conducted in prostate cancer will hopefully help to define this potential application better.

KEYWORDS 17AAG, geldanamycin, heat-shock protein 90, prostate cancer, renal cell carcinoma

\section{REVIEW CRITERIA}

Data for this review were identified from the PubMed database, which was searched for articles published from 1985 to April 2006. Only articles written in English were reviewed. Reference lists of relevant articles were checked for additional publications of interest. Search terms included "heat shock protein 90", "prostate cancer", and "kidney cancer". Specific publications not directly related to prostate or kidney cancer have also been included.

$J-B$ Lattouf is a Clinical Fellow in Urologic Oncology, R Srinivasan is Senior Investigator in Medical Oncology, PA Pinto is a Senior Investigator in Urologic Oncology, WM Linehan is Chief of Urologic Oncology, and L Neckers is a Principal Investigator at the Urologic Oncology Branch of the National Cancer Institute, National Institute of Health, Bethesda, MD, USA.

\section{Correspondence}

*Urologic Oncology Branch, National Cancer Institute, Room 1-5942, Building 10 CRC, 9000 Rockville Pike, Bethesda, MD 20892, USA

neckersı@mail.nih.gov

Received 29 June 2006 Accepted 14 August 2006

www.nature.com/clinicalpractice

doi:10.1038/ncpuro0604

\section{INTRODUCTION}

During the past 10-20 years there has been an explosion in the available data on characterization of molecular pathways in cancer cells. This phenomenon has paved the way to a new era of molecular therapeutic agents, with the development of novel compounds that target specific cellular pathways of critical importance in cancer-cell survival. Small molecules, such as multitargeted tyrosine-kinase inhibitors, have made their way from the bench into clinical trials and are now part of the standard clinical armamentarium available against a number of malignancies.

Targeted treatment for urologic cancer is now a reality of standard clinical practice. Most recently, two small-molecule inhibitors (sunitinib and sorafenib) that inhibit multiple receptor tyrosine kinases were approved by the FDA in December 2005 and January 2006 for clinical use in metastatic renal cancer. ${ }^{1,2}$ Other targeted strategies, such as cancer vaccines, are currently under investigation, and hold promise for prostate and kidney cancer treatment.

Heat-shock protein 90 (HSP90) is an abundant intracellular protein that is upregulated during cellular stress. ${ }^{3}$ Its role in cancer has received much attention in the past decade, given that it is an integral part of the machinery that allows neoplastic cells to escape normal regulation. HSP90 has functions in multiple oncogenic pathways, and might, therefore, be less of a 'moving target' than the other, everchanging components of the unstable genetic profile of a cancer cell. Well-characterized, selective inhibitors of HSP90 have completed phase I trials. To date, more than 20 phase II clinical trials of HSP90 inhibitors are planned or in progress, three of which are in urologic cancers. This article describes the role of HSP90 in urologic malignancy, with a special emphasis on the molecular pathways, the available clinical trials for HSP90 inhibitors, and the potential future avenues of investigation for these promising compounds. 


\section{BACKGROUND ON HSP9O}

HSP90 is a ubiquitous, constitutively expressed protein in eukaryotic cells. HSP90 comprises up to $1-2 \%$ of total cellular protein, a proportion that increases by $2-10$-fold during environmental stress; this upregulation seems to be a protective mechanism that enhances cell survival. ${ }^{3,4}$ Deletion of HSP90 has been shown to be lethal in eukaryotic cells, and chaperone proteins (such as HSP90) are upregulated in many neoplastic processes, ${ }^{5-7}$ as well as in urologic cancers in particular. ${ }^{8,9}$ These facts, considered together, point towards a possible protective role of heat-shock proteins in neoplastic processes. ${ }^{10}$

After their synthesis, proteins have to be folded in order to acquire their final, functional state. The role of HSP90 as a chaperone in the normal cell encompasses protein folding, translocation between cellular compartments, suppression of protein aggregation, and refolding of intermediate proteins. ${ }^{4} \mathrm{~A}$ folding pathway can either lead to a functional, properly folded client protein, or to degradation of the same molecule. ${ }^{11,12}$ During stress, this dual function helps repair (or 'cleanse') the pool of damaged proteins, and re-establishes homeostasis. ${ }^{12}$ Over 100 proteins have been reported to be clients of HSP90. Box 1 lists the most pertinent of these client proteins in urologic malignancy. A more detailed review is available in Wegele $\mathrm{H}$ et al., ${ }^{11}$ and on the website maintained by Picard. ${ }^{13}$ It is believed that mutations of specific client proteins in cancer are sustained by their interaction with HSP90, which might favor survival of a deregulated, neoplastic cell that harbors oncogenes. ${ }^{10}$
Box 1 Some HSP90 client proteins that are relevant to urologic malignancy.

- Androgen receptor 75

- Hypoxia-inducible factor 67,76

- Protein kinase $B^{77}$

- Mitogen-activated protein kinase kinases ${ }^{78}$

- Receptor tyrosine protein kinase erbB2 (also known as HER2/NEU) ${ }^{79}$

- Insulin-like growth factor 1 receptor 80

- C-met (hepatocyte growth factor receptor) ${ }^{81}$

The structure of HSP90 is illustrated in Figure 1; it is a $90 \mathrm{kDa}$ protein that consists of three distinct domains. ${ }^{14}$ The N-terminal domain contains an intrinsic ATP-binding site that has a crucial role in the protein's function; this role will be explained below. The middle domain contains a client-protein-binding site that can interact with ATP that is bound to the $\mathrm{N}$-domain. Finally, cytoplasmic HSP90 exists as a dimer, and it is through the C-terminal domain that dimerization occurs. ${ }^{14}$

Although HSP90 has a central role in clientprotein processing, it requires interactions with a host of other chaperones, co-chaperones and immunophilins, in order to perform these functions. Table 1 lists key components of the HSP90 protein-processing system. The client protein (a steroid receptor, in Figure 2) interacts first with an HSP70-HSP40 complex. ${ }^{15}$ This complex will then bind to HSP90 via a bridge protein called HOP (HSP90/HSP70 organizing protein). ${ }^{16}$ This intermediate form of the chaperone-receptor complex undergoes a conformational change through an ATP-

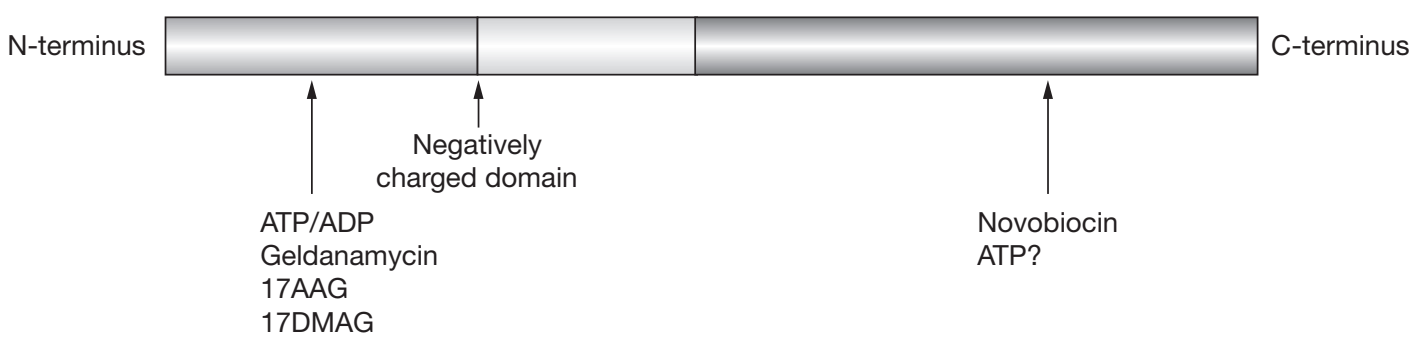

Figure 1 Schematic structure of HSP90. HSP90 has three distinct domains, and consists of the N-terminal, middle, and $\mathrm{C}$-terminal regions. A charged region exists between the $\mathrm{N}$-terminal and the middle domain. Benzoquinone ansamycins bind to the N-terminus, where ATP also binds. Novobiocin, a coumarin antibiotic, binds to the C-terminal domain. Homodimerization occurs at the C-terminal domain. Client proteins have been reported to interact with all three domains. Abbreviations: 17AAG, 17-allylamino-17demethoxygeldanamycin; 17DMAG, 17-dimethylaminoethylamino-17-demethoxygeldanamycin; HSP, heat-shock protein. 


\begin{tabular}{ll}
$\begin{array}{l}\text { Table } 1 \text { Components of the HSP90 chaperone } \\
\text { machinery. }{ }^{10}\end{array}$ \\
\hline Protein family & Class \\
\hline HSP90 & Chaperone \\
HSP70 & Chaperone \\
HSP40 & Co-chaperone \\
\hline HIP/Hop & Adapters \\
\hline CDC37 & Co-chaperone \\
\hline AHA1 & Co-chaperone \\
\hline FKBP51 & Immunophillin \\
\hline FKBP52 & Immunophillin \\
\hline P23 & Co-chaperone \\
\hline
\end{tabular}

Abbreviations: AHA1, activator of HSP90 ATPase homolog 1; CDC37, cell division cycle 37 homolog, also known as p50; FKBP, FK506 binding protein; HIP, HSP70 interacting protein; Hop, HSP70/HSP90-organizing protein; HSP, heat-shock protein

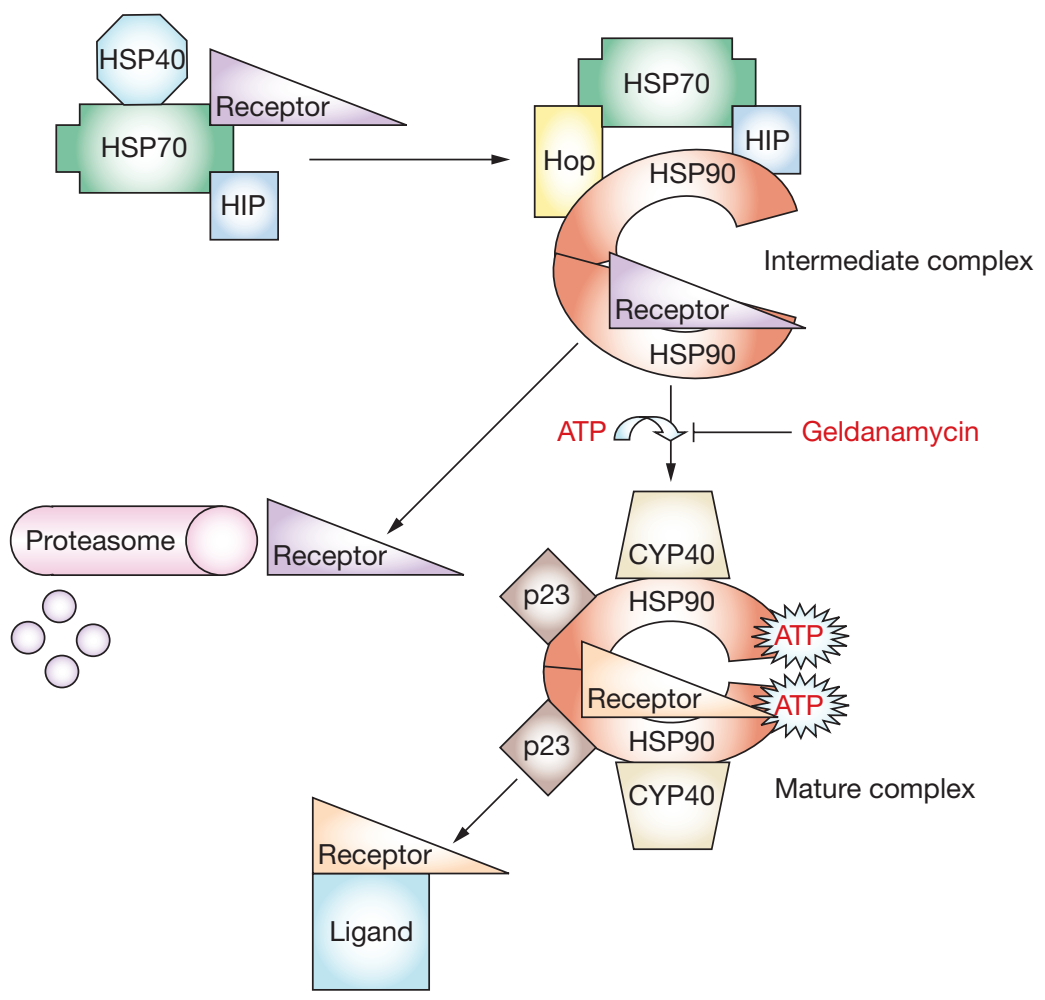

Figure 2 HSP90 machinery. HSP90 acts as a chaperone through binding of the HSP70-receptor complex via HOP, which forms an intermediate complex that can take one of two paths. The first path is initiated by HSP9O binding of ATP (and its ultimate hydrolysis); the client protein then acquires a mature conformation that allows it to bind its ligand. In the second path, if no ATP hydrolysis occurs, the receptor is either recycled through the chaperone machinery (not shown) or marked for degradation by the proteasome. Geldanamycin inhibits ATP binding and hydrolysis by the intermediate complex and, therefore, directs client proteins toward degradation. Abbreviations: CYP40, cyclophilin 40; HIP, Hsc70-interacting protein; Hop, HSP90/HSP70-organizing protein; HSP, heat-shock protein; p23, telomerase-binding protein. dependent process, which will significantly optimize receptor-ligand interaction. ${ }^{17}$ In its final conformation, the chaperone-receptor complex will proceed down one of two pathways: it will either bind its ligand and be released from the complex, in order to translocate inside the nucleus and initiate downstream gene transcription, or it will be recycled, through new chaperone interactions. If the ATP-dependent step does not take place, the receptor will eventually undergo ubiquitinylation (binding of the peptide ubiquitin to a protein, which marks it for destruction) and ultimately proteasome degradation (Figure 2). ${ }^{18,19}$ Probably one of the most critical steps in protein processing is, therefore, the ATP-dependent reaction that renders the chaperone-receptor complex capable of binding its ligand, and this is where HSP90 inhibitors exert their action.

\section{HEAT-SHOCK PROTEIN 90 INHIBITORS}

Multiple inhibitors of HSP90 have been described (see Box 2). For a more in-depth review of specific HSP90 inhibitors the reader is referred to a review published by Budillon et al. ${ }^{20}$ in 2005. Benzoquinone ansamycins are a class of antibiotics that have generated interest because of their ability to revert the malignant phenotype to a normal one, in fibroblasts transformed by Rous sarcoma virus. ${ }^{21}$ These antibiotics have also been shown to have HSP90-inhibiting activity. $^{22}$ Although controversy surrounded the mechanism of action of these first HSP90 inhibitors, it is now accepted that benzoquinone ansamycins act through the ATP-binding site in the $\mathrm{N}$-terminal domain of the chaperone. These agents prevent ATP binding ${ }^{23}$ and, therefore, result in targeting of client proteins for degradation by the proteasome. ${ }^{24}$ Observed effects of HSP90 inhibitors on tumors include cell-cycle arrest and apoptosis, as well as reduced invasion, angiogenesis and metastasis. ${ }^{25}$

Since HSP90 is essential for the function of normal cells as well as tumor cells, one initial concern in relation to its therapeutic applicability was that inhibition of its functions might not be selective for malignancy. It has, however, been shown through preclinical models that HSP90 inhibitors, given at certain doses, can exert antitumor activity without causing host toxicity. ${ }^{26}$ Furthermore, HSP90 inhibitors have been shown to concentrate more in tumor tissue than in normal tissue, ${ }^{27}$ which provides a unique opportunity for selective tumor 
targeting. Finally, HSP90 inhibitors bind with a significantly higher affinity to the chaperone in neoplastic cells than is evident in normal cells. ${ }^{28}$ This feature might be the result of increased activity of the chaperone machinery in the tumor cells, which could render tumor cells more vulnerable to HSP90 inhibition, compared with normal cells.

\section{Geldanamycin}

Geldanamycin was one of the first benzoquinone ansamycins to be isolated from actinomycete broth (Figure 3). ${ }^{29}$ This compound has shown antitumor activity in vitro as well as in vivo, ${ }^{30}$ but its hepatotoxicity profile in preclinical models precluded its use in clinical trials. ${ }^{30}$

\section{7-allylamino-17-demethoxygeldanamycin}

In a screening study that aimed to identify compounds with less toxicity than geldanamycin, 17-allylamino-17-demethoxygeldanamycin (17AAG) emerged as a promising candidate. ${ }^{31}$ This compound exhibited comparable biologic activity to geldanamycin, ${ }^{32}$ and had a morefavorable toxicity profile in vivo. Four phase I clinical trials of 17AAG as a single agent have been reported; ${ }^{33-36}$ these are outlined in Table 2. The recommended dosage of 17AAG in phase II studies has varied from $295-450 \mathrm{mg} / \mathrm{m}^{2}$ intravenously (depending on the treatment schedule), over a 28 -day cycle that included a 1 -week break from treatment. Reported adverse effects included fatigue, anemia, anorexia, diarrhea, nausea, vomiting, elevations in aspartate aminotransferase and alanine aminotransferase, thrombocytopenia, fever, and possible cardiac and pancreatic toxicity. At the recommended doses, however, 17AAG seemed to be well tolerated, with minimal adverse events. 17AAG is currently being investigated in phase II trials (Table 3 ) as a single agent and in combination, for the treatment of multiple solid tumors as well as leukemias and lymphomas.

\section{7-dimethylaminoethylamino-17- demethoxygeldanamycin}

Most recently, 17DMAG (17-dimethylaminoethylamino-17-demthoxygeldanamycin) has undergone comparison with 17AAG in vitro, and seems to retain the same capacity to bind HSP90 as 17AAG. ${ }^{37}$ Furthermore, being water soluble, this compound requires a less complex formulation than 17AAG, and has shown signs of oral bioavailability in vivo in a xenograft

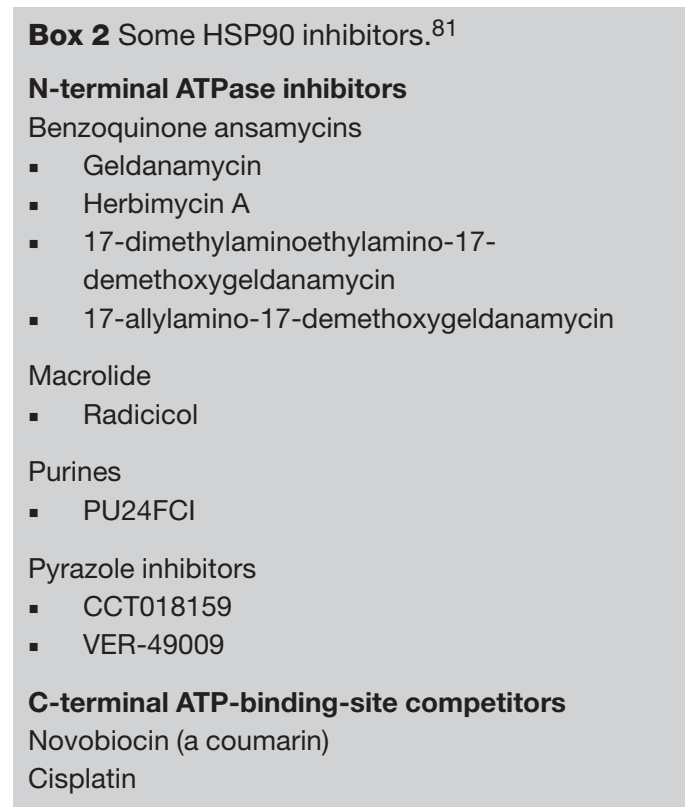

model in nude mice, which represents a significant potential advantage. ${ }^{38}$ Four phase I studies are underway to investigate the use of 17DMAG in solid tumors.

Other alternatives that inhibit HSP90 and are under development include purine analogs and pyrazole inhibitors of the N-terminal nucleotide pocket, and compounds that bind to a recently identified $\mathrm{C}$-terminal ATP-binding site (Box 2). ${ }^{39-42}$

\section{HSP9O IN PROSTATE CANCER}

\section{Androgen-resistant prostate cancer}

One of the current challenges in prostate cancer lies at the frontier of hormone-refractory disease. The transition between the hormone-sensitive and hormone-insensitive state implicates the androgen receptor as a central factor, and detailed reviews of the mechanisms of development of androgen-independent prostate cancer are available. ${ }^{43,44}$ Androgen-receptor expression is amplified in up to $30 \%$ of recurrent tumors after androgen deprivation therapy ${ }^{45}$ Although termed androgen-independent, there is evidence to suggest that hormone-refractory prostate cancer might still rely on stimulation of the androgen receptor for sustained growth. This stimulation could take place via ligand binding, ${ }^{46}$ or through binding of alternative molecules such as estrogens and progestins (or antiandrogens, in the case of mutated receptors). ${ }^{47}$ Activation through peptide growth factors or cytokines 
A<smiles>C/C(=C/C=C\C(C)C(OC(N)=O)C1CCC1)C(=O)NC1=CC(=O)C(C2CCC2)=C(CC(C)CC(C)C(O)C(C)/C=C(\C)C(C)O)C1=O</smiles>

$\begin{array}{ll}\text { Geldanamycin } & \mathrm{R}=\mathrm{CH}_{3} \mathrm{O} \\ \text { 17AAG } & \mathrm{R}=\mathrm{NHCH}_{2} \mathrm{CH}=\mathrm{CH}_{2} \\ \text { 17DMAG } & \mathrm{R}=\mathrm{NHCH}_{2} \mathrm{CH}_{2} \mathrm{~N}\left(\mathrm{CH}_{3}\right)_{2}\end{array}$

B

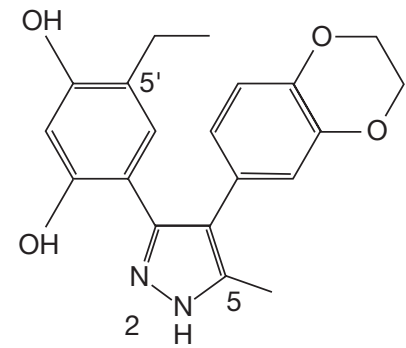

3,4-Diaryl pyrazole CCT018159<smiles>[X][Y4](Oc1ccc([X])cc1)c1nc2c([Y])nc([Y])nc2n1[X]</smiles>

Purine (class)

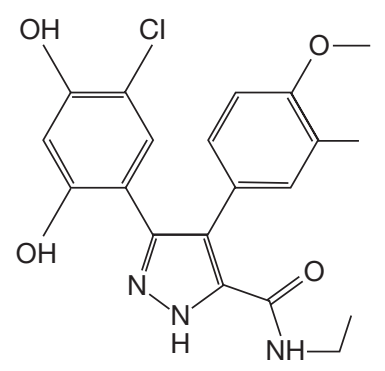

VER-49009

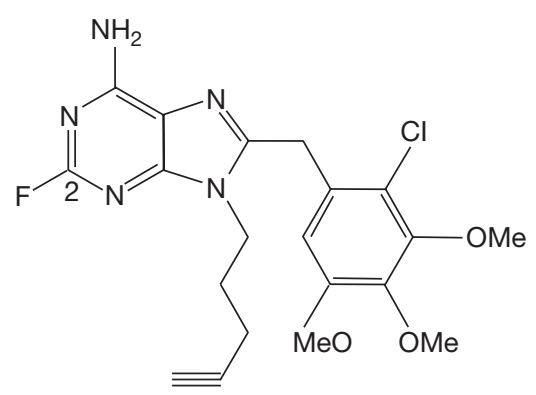

$\mathrm{PU} 24 \mathrm{FCl}$

Figure 3 HSP90 inhibitors. (A) Some benzoquinone ansamycins. (B) Pyrazole inhibitors. (C) Purines. Abbreviations: 17AAG, 17-allylamino17-demethoxygeldanamycin; 17DMAG, 17-dimethylaminoethylamino-17demethoxygeldanamycin.

however, a subset of hormone-refractory prostate cancers that might not depend on androgenreceptor expression. These tumors sustain their growth in a way that allows them to bypass the androgen receptor entirely, by using other pathways including the phosphatidylinositol-3 kinase (PI3K)/AKT and STAT3 (signal transducer and activator of transcription 3) pathways. ${ }^{52}$

Considering this level of complexity, an ideal treatment for hormone-refractory prostate cancer should target the multiple mechanisms involved in progression to the androgenindependent state. HSP90 inhibitors seem to be promising candidates to achieve this effect, since they inhibit nodal points in multiple survival pathways.

\section{Androgen receptor-HSP90 interaction}

The androgen receptor is a client protein of HSP90, and immunohistochemical staining shows that HSP90 is strongly expressed in prostate cancer tissues of all Gleason grades. ${ }^{53}$ Studies in vitro and in vivo have confirmed that geldanamycin and 17AAG cause degradation of the androgen receptor in three different prostate cancer cell lines. ${ }^{54}$ Not only does 17AAG downregulate the wild-type androgen receptor, but it also has the same effect on mutated androgen receptors. ${ }^{54}$

Beyond the direct effect on the androgen receptor, inhibition of HSP90 shows activity at other critical checkpoints in the hormoneresistant cell. HER2/NEU and AKT levels decline after 17AAG administration both in vivo and in vitro. ${ }^{54}$ These changes have been observed in correlation with downregulation of the androgen receptor and tumor xenograft inhibition. Although it has not been shown that HSP90 inhibitors downregulate other signaling molecules that are known to be crucial to the hormone-refractory state in prostate cancer cell lines, such downregulation has been established in other models (e.g. IGF1 ${ }^{55}$ and STAT3 ${ }^{56}$ ). Taken together, these facts constitute a solid rationale for testing HSP90 inhibitors in prostate cancer.

\section{Additive effect of HSP90 inhibitors with radiotherapy and chemotherapy}

HSP90 inhibition should be considered in combination with existing treatments for prostate cancer. Since standard treatments (e.g. hormonal ablation and chemotherapy) have numerous adverse effects, and since it is likely 
Table 2 Summary of the clinical phase I studies of 17AAG in urologic malignancy.

\begin{tabular}{llllll}
\hline Phase I & $\begin{array}{l}\text { Number of patients } \\
\text { with urologic } \\
\text { malignancy (type) }\end{array}$ & $\begin{array}{l}\text { Treatment } \\
\text { regimen }\end{array}$ & $\begin{array}{l}\text { Recommended } \\
\text { dose for phase II } \\
\text { (mg/m2 IV) }\end{array}$ & Response & Status \\
\hline $\begin{array}{l}\text { Grem et al. } \\
(2005)^{35}\end{array}$ & 2 (Renal) & $\begin{array}{l}5 \text { days per week, } \\
\text { every 3 weeks }\end{array}$ & 40 & $\begin{array}{l}\text { No objective } \\
\text { response noted }\end{array}$ & Completed \\
$\begin{array}{l}\text { Goetz et al. } \\
(2005)^{34}\end{array}$ & $\begin{array}{l}\text { 0 (Non-urologic } \\
\text { cancer) }\end{array}$ & $\begin{array}{l}\text { Days 1, 8 and 15 } \\
\text { of a 28-day cycle }\end{array}$ & 308 & $\begin{array}{l}\text { No objective } \\
\text { response noted }\end{array}$ & Completed \\
$\begin{array}{l}\text { Banerji et al. } \\
(2005)^{33}\end{array}$ & 1 (Renal) & $\begin{array}{l}\text { Once a week, no } \\
\text { break, 4-week } \\
\text { cycle }\end{array}$ & $\begin{array}{l}\text { No objective } \\
\text { response noted }\end{array}$ & Completed \\
$\begin{array}{l}\text { Ramanathan } \\
\text { et al. (2005) }\end{array}$ & 7 (Genitourinary) & $\begin{array}{l}\text { 3 doses per week } \\
\text { in 4-week cycle }\end{array}$ & 295 & $\begin{array}{l}\text { No objective } \\
\text { response noted }\end{array}$ & Completed \\
\hline Abbreviations: 17AAG, 17-allylamino-17-demethoxygeldanamycin; IV, intravenous. & & \\
\hline
\end{tabular}

Table 3 Summary of the clinical phase II studies of 17AAG in urologic malignancy.

\begin{tabular}{lllll}
\hline Institution & Malignancy treated & Treatment regimen & $\begin{array}{l}\text { Dose } \\
\mathbf{( m g / \mathbf { m } ^ { 2 }} \mathbf{~ I V )}\end{array}$ & Status \\
\hline Mayo Clinic & $\begin{array}{l}\text { Metastatic, hormone-refractory } \\
\text { prostate cancer }\end{array}$ & $\begin{array}{l}\text { Days 1, 8 and 15 } \\
\text { of a 28-day cycle }\end{array}$ & 300 & Ongoing \\
$\begin{array}{l}\text { Memorial } \\
\text { Sloan-Kettering }\end{array}$ & $\begin{array}{l}\text { Metastatic, clear cell or papillary } \\
\text { renal cell carcinoma }\end{array}$ & $\begin{array}{l}\text { Days 1, 4, 8 and 11 of } \\
\text { a 21-day cycle }\end{array}$ & 220 & Completed \\
NIH & $\begin{array}{l}\text { Localized, renal clear cell carcinoma } \\
\text { in von Hippel-Lindau patients }\end{array}$ & $\begin{array}{l}\text { Days 1, 8 and 15 } \\
\text { of a 28-day cycle }\end{array}$ & 300 & Ongoing \\
\hline
\end{tabular}

Abbreviations: 17AAG, 17-allylamino-17-demethoxygeldanamycin; IV, intravenous.

that tumors will progress in most patients despite treatment with these standard therapies, exploration of treatment approaches that can be used in combination with standard treatments is certainly warranted.

Since neoplastic cells rely on the HSP90 machinery to sustain oncogene products, inhibition of HSP90 function might render the neoplastic cell more vulnerable to standard antineoplastic treatments, including radiotherapy or chemotherapy. Proof of this effect has been noted in vitro with various prostate cancer and other tumor cell lines. ${ }^{57,58}$

\section{Clinical trials in prostate cancer}

Following on from the solid rationale for use of HSP90 inhibitors in prostate cancer, and the encouraging preclinical in vitro and in vivo studies, a phase II trial has been initiated to test the efficacy of 17AAG monotherapy in the setting of metastatic, hormone-refractory prostate cancer. ${ }^{59}$ The study aims to assess the PSA response to 17AAG in patients who have failed primary chemotherapy. Secondary objectives are to determine overall survival, disease-free survival and measurable disease response to 17AAG, as well as to study various markers, such as nuclear factor $\kappa \mathrm{B}$, interleukin 6 , and maspin. In addition to this, a phase I combination study of 17AAG and docetaxel at Memorial SloanKettering Cancer Center is currently recruiting patients with hormone-refractory prostate cancer or other solid tumors.

\section{HSP9O IN KIDNEY CANCER}

\section{Molecular pathways in kidney cancer}

Insight gained through studies of hereditary kidney cancer has shed light on the pathways that are critical in sporadic kidney cancer. Two hereditary syndromes, von Hippel-Lindau (VHL) and hereditary papillary renal cancer, will be discussed, which both have potential for HSP90-targeted therapy.

\section{Von Hippel-Lindau disease}

VHL disease is a hereditary disorder with an autosomal-dominant transmission. Clinical manifestations in this condition include central nervous system lesions (retinal angiomas, cerebellar and spinal hemangioblastomas), and 
www.nature.com/clinicalpractice/uro

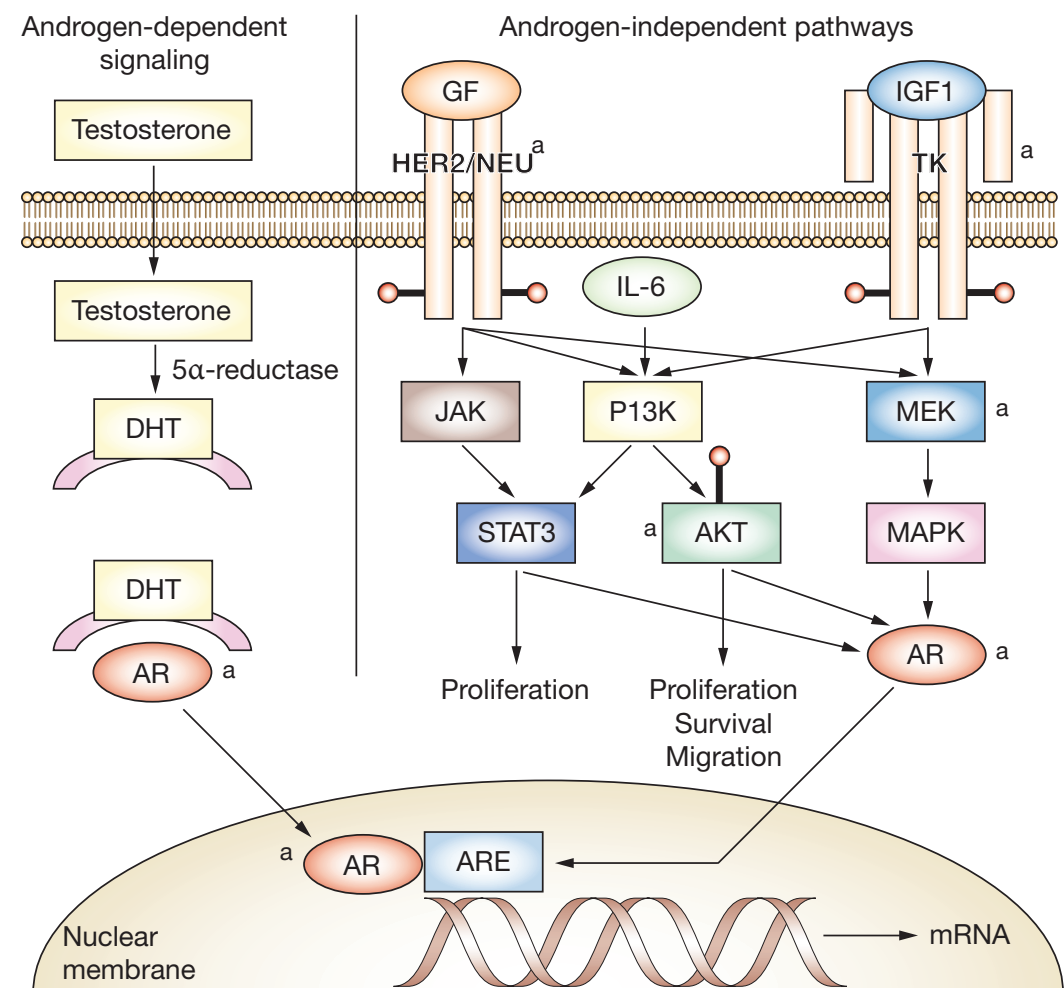

Figure 4 Androgen-receptor signaling in prostate cancer. Hormone-dependent androgen signaling takes place through dihydrotestosterone stimulation of the androgen receptor (left panel). Hormone-refractory prostate cancer cells survive through stimulation of multiple signaling pathways, including the PI3K and the MAPK pathways. These culminate in androgen-receptor signaling, or alternate pathways that lead to cell proliferation, migration and survival (right panel). aHSP90-inhibitor-sensitive protein or pathway. Abbreviations: AKT, protein kinase B; AR, androgen receptor; ARE, androgen response element; $\mathrm{DHT}$, dihydrotestosterone; GF, growth factor; IGF1, insulin-like growth factor 1; IL-6, interleukin 6; JAK, Janus kinase; MAPK, mitogen-activated protein kinase; MEK, upstream kinases of mitogen-activated protein kinases, also known as MAP2Ks; P13K, phosphatidylinositol 3 kinase; mRNA, messenger RNA; STAT3, signal transducer and activator of transcription 3; TK, tyrosine kinase.

visceral lesions (pancreatic cysts and neuroendocrine tumors, adrenal and extra-adrenal pheochromocytomas, renal cysts and clear cell carcinoma). Other findings include cystadenomas of the epididymis and broad ligament, and endolymphatic sac tumors of the inner ear. ${ }^{60} \mathrm{VHL}$ disease is one of the rare conditions for which a defined intracellular pathway has been delineated over the past few years (Figure 5).The product of the VHL gene, pVHL, is constitutively expressed; it targets hypoxiainducible factor (HIF) for degradation via the proteasome pathway. In the absence of VHL, HIF is stabilized and upregulates (among other things) the expression of downstream products such as vascular epithelial growth factor, transforming growth factor $\alpha$ and glucose transporter type 1 that generate neovascularization, mitogenesis and increased glucose uptake respectively. All these events drive tumor development and growth. ${ }^{61}$ Targeting HIF for degradation is a potentially promising strategy in a mechanistic approach to this disease. Furthermore, since VHL mutations have been described in up to $57 \%$ of sporadic, clear-cell kidney tumors, ${ }^{62}$ such a strategy could hold promise for the broader patient population with sporadic, clear-cell renal carcinoma.

\section{Sporadic, papillary type I renal cancer}

Sporadic, papillary type I renal cancer is the second most common type of renal cancer; ${ }^{63}$ and shares a distinct morphologic phenotype with hereditary papillary renal cell carcinoma (HPRC). ${ }^{64}$ HPRC is an autosomal dominant disorder with reduced penetrance; the clinical manifestations of HPRC include bilateral multifocal kidney tumors with a papillary type I histology. The HPRC oncogene was located by linkage analysis on chromosome 7q31.1-34, and missense mutations in the tyrosine kinase domain of MET proto-oncogene (which encodes c-met) were detected in individuals with HPRC. ${ }^{65} \mathrm{C}$-met is a membrane receptor tyrosine kinase that binds extracellular hepatocyte growth factor, which triggers autophosphorylation, and a downstream cascade that culminates in increased mitogenesis, motogenesis and morphogenic differentiation (Figure 6). ${ }^{66}$ Targeting c-met might, therefore, be a rational strategy to tackle this pathway.

\section{Clinical trials in kidney cancer}

As shown in Box 1, 17AAG is a potent inhibitor of both HIF and c-met, which are both client proteins of HSP90. HIF downregulation by 17AAG has been demonstrated in a renal cell carcinoma cell line, and is independent of the VHL ubiquitinylation pathway. ${ }^{67}$ Unfortunately, no in vivo xenograft model to specifically assess the activity of 17AAG in clear cell cancer has been reported. Phase I trials with 17AAG have not included sufficient numbers of patients with kidney cancer to permit speculation on its efficacy in this setting (Box 2).

A phase II study is being conducted at the National Cancer Institute that will, hopefully, help to answer this question. The objective of this study is to evaluate the efficacy of 17AAG 
in patients with VHL disease who harbor localized renal tumors. Patients are required to have no metastatic disease and to be candidates for local surgical resection in order to enroll in this trial. Outcomes include a measurable disease response of the target renal tumors, as well as pharmacokinetic and pharmacodynamic studies-these represent a very exciting end point, since tissue samples are rarely available in such studies. This study will hopefully help to amass insight into the modulation of oncogenic pathways within tumors. Another phase II trial conducted at the Memorial Sloan-Kettering Cancer Center has just been completed. This study evaluated the efficacy of 17AAG in patients with metastatic clear cell or papillary renal cell carcinoma. Results from this study are awaiting publication.

Although c-met has been shown to be a client protein of HSP90, ${ }^{68}$ the role of HSP90 inhibition in papillary type I kidney cancer has not been formally explored. This area remains to be investigated in the future.

\section{HSP9O IN OTHER UROLOGIC MALIGNANCIES}

\section{Transitional cell carcinoma of the bladder}

Controversy exists over the role of HSP90 in bladder cancer. In an immunohistochemical study of HSP90 expression in urothelial cancer, the HSP90 chaperone was found to be expressed in normal tissue but was expressed to a greater extent in neoplastic cells. ${ }^{69}$ In fact, this study showed that low levels of HSP90 expression in tumor specimens correlated with a poor prognosis. Different results were reported in another study that used the same detection methods, where the authors concluded that HSP90 staining was absent in normal tissue and present in tumors, with the strength of staining correlating positively with tumor grade. ${ }^{70}$ Further studies are needed to understand the role of HSP90 in transitional cell carcinoma.

\section{Testis cancer}

High levels of expression of HSP90 have been reported in human embryonal carcinoma cell lines. ${ }^{71,72}$ No in vitro studies are available that have studied the effects of geldanamycin analogs in these cell lines. Given the high rate of cure in nonseminomatous as well as seminomatous germ-cell tumors, interest in targeting HSP90 might lie in the rare cases where all

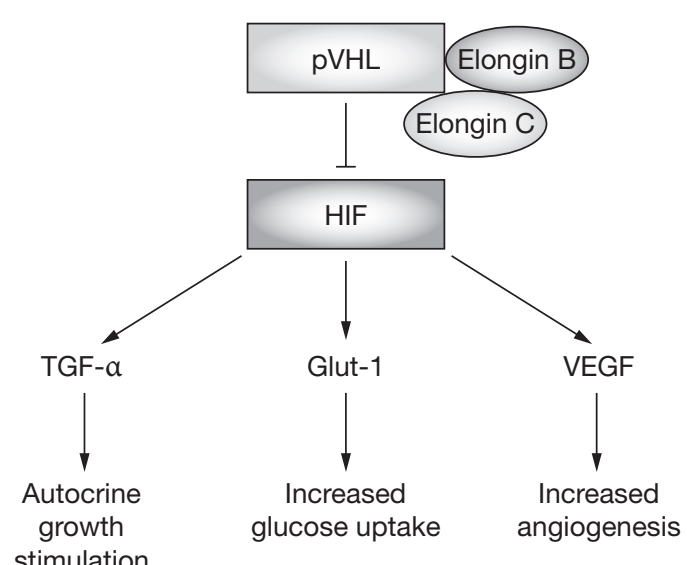

Figure 5 The von Hippel-Lindau pathway in clear cell kidney cancer. The protein product of the $\mathrm{VHL}$ gene (pVHL) is a component of the ubiquitin ligase complex that targets HIF for degradation. In the absence of pVHL, HIF will not be downregulated, and will drive the transcription of downstream factors such as TGF- $\alpha$, Glut-1 and VEGF, which lead to growth stimulation, increased glucose uptake and increased angiogenesis respectively. Abbreviations: Glut-1, glucose transporter 1; HIF, hypoxia-inducible factor; pVHL, von Hippel-Lindau protein; TGF- $\alpha$, transforming growth factor alpha; VEGF, vascular endothelial growth factor.

treatment modalities have failed. In such a scenario, further investigations into the role of HSP90 could hold promise.

\section{PHARMACODYNAMIC EVALUATION OF ANTI-HSP9O ACTIVITY IN UROLOGIC MALIGNANCIES}

Unlike other molecularly targeted agents that have been introduced in the treatment of urologic cancers, the efficacy of HSP90 inhibitors is probably a result of chaperone inhibition, which can affect a number of HSP90 client proteins. HSP90 activity in vivo can only be measured indirectly, by monitoring the activity and/or stability of one or more of its client proteins. Informative pharmacodynamic evaluation of HSP90 inhibition in the context of urologic malignancies must, therefore, take into account the tumor type and its etiology. While pharmacodynamic monitoring of peripheral blood lymphocytes has provided a readily accessible and reproducible index of in vivo biologic activity of HSP90 inhibitors in phase I clinical trials, drug effects in this normal tissue do not necessarily predict tumor-specific activity. 
www.nature.com/clinicalpractice/uro

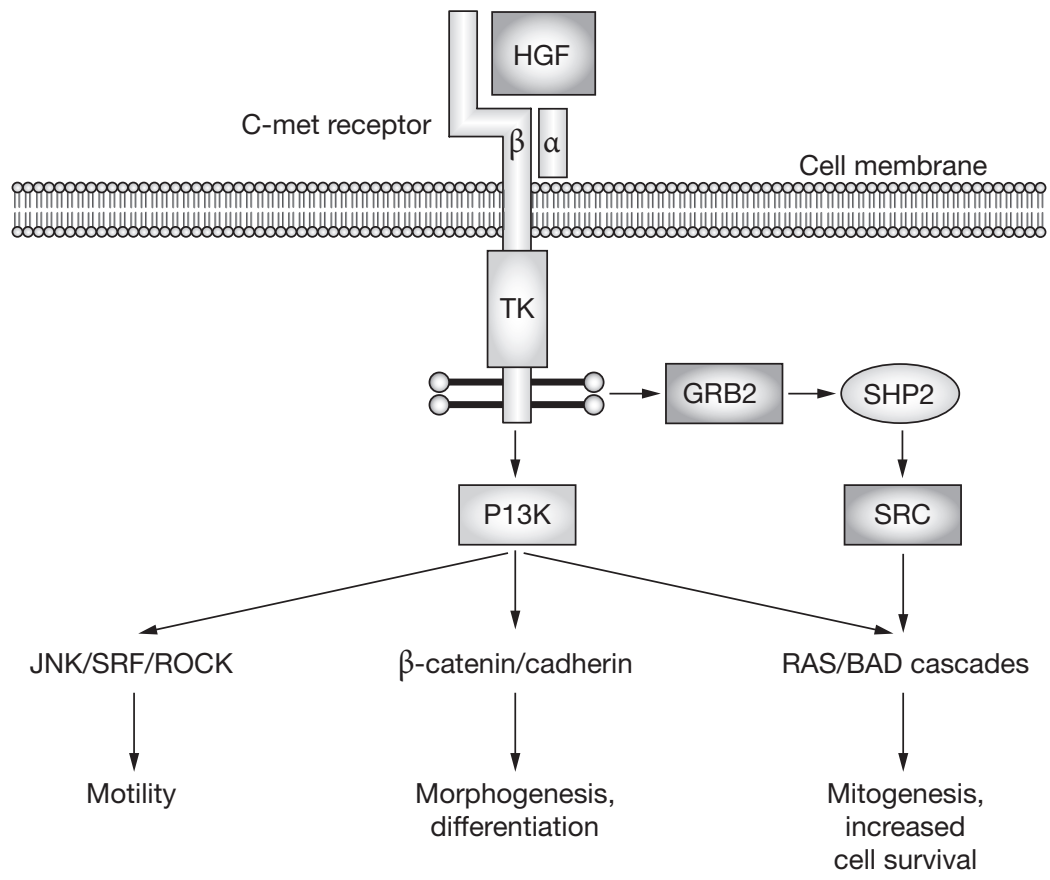

Figure $6 \mathrm{C}$-met signaling in hereditary papillary renal carcinoma. C-met receptor stimulation (by hepatocyte growth factor) will result in autophosphorylation of the tyrosine kinase domains of the receptor, leading to downstream cascades that result in dedifferentiation, increased motility, mitogenesis, and prolonged cell survival. Abbreviations: BAD, Bcl2 antagonist of cell death; GRB2, growth factor receptor-bound protein 2; HGF, hepatocyte growth factor; JNK, c-Jun N-terminal kinase; P13K, phosphatidylinositol 3 kinase; Ras, a small GTPase; ROCK, Rho kinase; SHP2, SH2-containing protein-tyrosine phosphatase 2; Src, a tyrosine kinase (oncogene); SRF, serum response factor; TK, tyrosine kinase.

In the context of prostate cancer, therefore, it would be important to monitor drug effects on one or more end points in tumor biopsies: androgen-receptor protein expression, phosphorylation status of protein kinase B, HER2/NEU expression, MAP kinase activation status, and phosphorylation status of STAT3. These evaluations can be made by techniques such as immunocytochemistry or tissue microarrays.

In the context of kidney cancer (depending on tumor subtype), c-met receptor expression, HIF protein expression, or expression of HIF target genes-such as those for glucose transporter type 1 and transforming growth factor $\alpha-$ can be monitored. Imaging studies could be considered, to determine changes in neovascularization or glucose uptake. Similar pharmacodynamic end points for transitional cell carcinoma of the bladder and testis cancer need to be developed, based on careful preclinical evaluation of the response of these tumors to HSP90 inhibitors.

\section{IMPACT OF GENE POLYMORPHISMS ON RESPONSES TO DRUGS}

Cytochrome P4503A5 (CYP3A5 ${ }^{\star} 3$ ) polymorphism might contribute to interindividual differences in CYP3A-dependent drug clearance. Goetz et al. have, however, determined that while $C Y P 3 A 5^{\star} 3$ polymorphism could alter exposure to $17 \mathrm{AAG}$, this is unlikely to have clinical consequences since $17 \mathrm{AG}$ (the metabolite of 17AAG) is also bioactive. ${ }^{34}$ Likewise, although $\mathrm{NAD}(\mathrm{P}) \mathrm{H}$ quinone oxidoreductase 1 (NQO1) expression has been shown to affect in vitro sensitivity of tumor cells to $17 \mathrm{AAG},{ }^{25}$ in their phase I clinical trial Goetz et al. found no difference in drug clearance or toxicity in patients whose cells exhibited decreased NQO1 enzyme activity. ${ }^{34}$ It remains to be determined, however, whether NQO1 expression level sensitizes tumor cells to this drug in vivo.

The potential impact on drug sensitivity of polymorphisms in the family of HSP90 genes should also be considered. To date, a low variability has been observed in the coding regions of both HSP90A and HSP90B alleles. ${ }^{73}$ For HSP90A, only one missense and one nonsense mutation have been observed. The missense mutant has compromised activity when tested in yeast, ${ }^{74}$ but the individual who carried this mutation was a healthy adult. A single missense mutation in $H S P 90 B$ that resulted in a conservative amino acid change has been reported. Importantly, all of these mutations are in the $\mathrm{C}$-terminal portion of the protein; no mutations in the $\mathrm{N}$-terminal (drug-binding) domains have been identified, to date. The absence of variability in the $\mathrm{N}$-terminal domain (if confirmed) is important for pharmacogenetic reasons. The response of the HSP90A C-terminal missense mutation to $\mathrm{N}$-terminal-inhibitor drugs, however, remains to be determined.

\section{CONCLUSION}

The era of targeted molecular therapy potentially holds great promise in the treatment of cancer. HSP90 is an attractive target for the treatment of urologic malignancies, including prostate and kidney cancer. 17AAG is an inhibitor of HSP90 that is currently under investigation for activity in humans as a monotherapy, as well as in combination with other chemotherapeutic agents. The development of this compound, and of other HSP90 inhibitors-from bench to clinic-constitutes a model of translational research that serves as a paradigm for the discovery and validation of new, molecularly targeted cancer drugs. 


\section{KEY POINTS}

- HSP90 is a ubiquitous intracellular protein that is essential for the processing of normal proteins as well as oncogenes

- HSP90 acts on multiple nodal points in cancer pathways, and constitutes a more attractive therapeutic target than individual small molecules

- Inhibitors of HSP90 have shown antineoplastic activity in vitro and in vivo, have completed phase I trials, and are being tested for efficacy as monotherapy in prostate and kidney cancers

- Combinations of HSP90 inhibitors with other chemotherapeutic agents have a solid rationale for therapeutic use and might hold promise in prostate as well as kidney cancer

\section{References}

1 FDA (online 20 December 2005) FDA approves new treatment for advanced kidney cancer. [http:// www.fda.gov/bbs/topics/NEWS/2005/NEW01282.html] (accessed 17 August 2006)

2 FDA (online 26 January 2006) FDA approves new treatment for gastrointestinal and kidney cancer. [http://www.fda.gov/bbs/topics/news/2006/ NEW01302.html] (accessed 17 August 2006)

3 Welch WJ and Feramisco JR (1982) Purification of the major mammalian heat shock proteins. $J$ Biol Chem 257: 14949-1459

4 Buchner J (1999) Hsp90 \& Co-a holding for folding. Trends Biochem Sci 24: 136-141

5 Kimura E et al. (1993) Correlation of the survival of ovarian cancer patients with mRNA expression of the 60-kD heat-shock protein HSP-60. J Clin Oncol 11: 891-898

6 Ciocca DR et al. (1993) Heat shock protein hsp70 in patients with axillary lymph node-negative breast cancer: prognostic implications. J Nat/ Cancer Inst 85: $570-574$

7 Ralhan R and Kaur J (1995) Differential expression of $\mathrm{Mr} 70,000$ heat shock protein in normal, premalignant, and malignant human uterine cervix. Clin Cancer Res 1: 1217-1222

8 Santarosa M et al. (1997) Expression of heat shock protein 72 in renal cell carcinoma: possible role and prognostic implications in cancer patients. Eur $J$ Cancer 33: 873-877

9 Rocchi P et al. (2004) Heat shock protein 27 increases after androgen ablation and plays a cytoprotective role in hormone-refractory prostate cancer. Cancer Res 64: 6595-6602

10 Whitesell L and Lindquist SL (2005) HSP9O and the chaperoning of cancer. Nat Rev Cancer 5: 761-772

11 Wegele Het al. (2004) Hsp70 and Hsp90-a relay team for protein folding. Rev Physiol Biochem Pharmacol 151: 1-44

12 Jolly C and Morimoto RI (2000) Role of the heat shock response and molecular chaperones in oncogenesis and cell death. J Nat/ Cancer Inst 92: 1564-1572

13 Picard D (online July 2006) Hsp90 interactors. [http:// www.picard.ch/downloads/Hsp90interactors.pdf] (accessed 17 August 2006)

14 Prodromou C and Pearl LH (2003) Structure and functional relationships of Hsp90. Curr Cancer Drug Targets 3: 301-323
15 Hernandez MP et al. (2002) The assembly and intermolecular properties of the hsp70-Hop-hsp90 molecular chaperone complex. J Biol Chem 277: 38294-38304

16 Smith DF et al. (1993) Identification of a 60-kilodalton stress-related protein, p60, which interacts with hsp90 and hsp70. Mol Cell Biol 13: 869-876

17 Panaretou $B$ et al. (1998) ATP binding and hydrolysis are essential to the function of the Hsp90 molecular chaperone in vivo. EMBO J 17: 4829-4836

18 Mimnaugh EG et al. (1996) Polyubiquitination and proteasomal degradation of the $\mathrm{p} 185 \mathrm{c}$-erbB-2 receptor protein-tyrosine kinase induced by geldanamycin. J Biol Chem 271: 22796-22801

19 Xu W et al. (2002) Chaperone-dependent E3 ubiquitin ligase CHIP mediates a degradative pathway for c-ErbB2/Neu. Proc Natl Acad Sci USA 99: 12847-12852

20 Budillon A et al. (2005) Multiple-target drugs: inhibitors of heat shock protein 90 and of histone deacetylase. Curr Drug Targets 6: 337-351

21 Uehara Y et al. (1985) Screening of agents which convert 'transformed morphology' of Rous sarcoma virus-infected rat kidney cells to 'normal morphology': identification of an active agent as herbimycin and its inhibition of intracellular src kinase. Jpn J Cancer Res 76: 672-675

22 Whitesell Let al. (1994) Inhibition of heat shock protein HSP90-pp60v-src heteroprotein complex formation by benzoquinone ansamycins: essential role for stress proteins in oncogenic transformation. Proc Natl Acad Sci USA 91: 8324-8328

23 Grenert JP et al. (1997) The amino-terminal domain of heat shock protein 90 (hsp90) that binds geldanamycin is an ATP/ADP switch domain that regulates hsp90 conformation. J Biol Chem 272: 23843-23850

24 Mimnaugh EG et al. (1996) Polyubiquitination and proteasomal degradation of the $\mathrm{p} 185 \mathrm{c}$-erbB-2 receptor protein-tyrosine kinase induced by geldanamycin. J Biol Chem 271: 22796-22801

25 Maloney A and Workman P (2002) HSP90 as a new therapeutic target for cancer therapy: the story unfolds. Expert Opin Biol Ther 2: 3-24

26 Kelland LR et al. (1999) DT-diaphorase expression and tumor cell sensitivity to 17-allylamino, 17-demethoxygeldanamycin, an inhibitor of heat shock protein 90. J Natl Cancer Inst 91: 1940-1949

27 Eiseman JL et al. (2005) Pharmacokinetics and pharmacodynamics of 17-demethoxy 17-[[(2-dimet hylamino)ethyl]amino]geldanamycin (17DMAG, NSC 707545) in C.B-17 SCID mice bearing MDA-MB-231 human breast cancer xenografts. Cancer Chemother Pharmacol 55: 21-32

28 Kamal A et al. (2003) A high-affinity conformation of Hsp90 confers tumour selectivity on Hsp90 inhibitors. Nature 425: 407-410

29 DeBoer C et al. (1970) Geldanamycin, a new antibiotic. J Antibiot (Tokyo) 23: 442-447

30 Supko JG et al. (1995) Preclinical pharmacologic evaluation of geldanamycin as an antitumor agent. Cancer Chemother Pharmacol 36: 305-315

31 Schnur RC et al. (1995) Inhibition of the oncogene product p185erbB-2 in vitro and in vivo by geldanamycin and dihydrogeldanamycin derivatives. J Med Chem 38: 3806-3812

32 Schulte TW and Neckers LM (1998) The benzoquinone ansamycin 17-allylamino-17-demethoxygeldanamycin binds to HSP9O and shares important biologic activities with geldanamycin. Cancer Chemother Pharmacol 42: 273-279

33 Banerji U et al. (2005) Phase I pharmacokinetic and pharmacodynamic study of 17-allylamino, 17-demethoxygeldanamycin in patients with advanced malignancies. J Clin Oncol 23: 4152-4161 
34 Goetz MP et al. (2005) Phase I trial of 17-allylamino17-demethoxygeldanamycin in patients with advanced cancer. J Clin Oncol 23: 1078-1087

35 Grem JL et al. (2005) Phase I and pharmacologic study of 17-(allylamino)-17-demethoxygeldanamycin in adult patients with solid tumors. $J$ Clin Oncol 23: 1885-1893

36 Ramanathan RK et al. (2005) Phase I pharmacokinetic-pharmacodynamic study of 17-(allylamino)-17-demethoxygeldanamycin (17AAG, NSC 330507), a novel inhibitor of heat shock protein 90 , in patients with refractory advanced cancers. Clin Cancer Res 11: 3385-3391

37 Smith Vet al. (2005) Comparison of 17dimethylaminoethylamino-17-demethoxygeldanamycin (17DMAG) and 17-allylamino-17demethoxygeldanamycin (17AAG) in vitro: effects on Hsp90 and client proteins in melanoma models. Cancer Chemother Pharmacol 56: 126-137

38 Hollingshead $\mathrm{M}$ et al. (2005) In vivo antitumor efficacy of 17-DMAG (17-dimethylaminoethylamino-17demethoxygeldanamycin hydrochloride), a watersoluble geldanamycin derivative. Cancer Chemother Pharmacol 56: 115-125

39 Marcu MG et al. (2000) Novobiocin and related coumarins and depletion of heat shock protein 90-dependent signaling proteins. J Nat/ Cancer Inst 92: 242-248

40 Soti C et al. (2002) A nucleotide-dependent molecular switch controls ATP binding at the C-terminal domain of Hsp90. N-terminal nucleotide binding unmasks a C-terminal binding pocket. J Biol Chem 277: 7066-7075

41 Barril X et al. (2006) 4-Amino derivatives of the Hsp90 inhibitor CCT018159. Bioorg Med Chem Lett 16: 2543-2548

42 Vilenchik M et al. (2004) Targeting wide-range oncogenic transformation via $\mathrm{PU} 24 \mathrm{FCl}$, a specific inhibitor of tumor Hsp90. Chem Biol 11: 787-797

43 Feldman BJ and Feldman D (2001) The development of androgen-independent prostate cancer. Nat Rev Cancer 1: 34-45

44 Grossmann ME et al. (2001) Androgen receptor signaling in androgen-refractory prostate cancer. J Natl Cancer Inst 93: 1687-1697

45 Visakorpi T et al. (1995) In vivo amplification of the androgen receptor gene and progression of human prostate cancer. Nat Genet 9: 401-406

46 Gregory CW et al. (2001) Androgen receptor stabilization in recurrent prostate cancer is associated with hypersensitivity to low androgen. Cancer Res 61: 2892-2898

47 Veldscholte J et al. (1992) The androgen receptor in $\mathrm{LNCaP}$ cells contains a mutation in the ligand binding domain which affects steroid binding characteristics and response to antiandrogens. J Steroid Biochem Mol Biol 41: 665-669

48 Culig Z et al. (1994) Androgen receptor activation in prostatic tumor cell lines by insulin-like growth factor-I, keratinocyte growth factor, and epidermal growth factor. Cancer Res 54: 5474-5478

49 Yeh S et al. (1999) From HER2/Neu signal cascade to androgen receptor and its coactivators: a novel pathway by induction of androgen target genes through MAP kinase in prostate cancer cells. Proc Natl Acad Sci USA 96: 5458-5463

50 Wen $\mathrm{Y}$ et al. (2000) HER-2/neu promotes androgenindependent survival and growth of prostate cancer cells through the Akt pathway. Cancer Res 60 : 6841-6845

51 Signoretti S et al. (2000) Her-2-neu expression and progression toward androgen independence in human prostate cancer. J Natl Cancer Inst 92: 1918-1929
52 Spiotto MT and Chung TD (2000) STAT3 mediates IL-6-induced neuroendocrine differentiation in prostate cancer cells. Prostate 42: 186-195

53 Thomas SA et al. (1996) Detection and distribution of heat shock proteins 27 and 90 in human benign and malignant prostatic tissue. Br J Urol 77: 367-372

54 Solit DB et al. (2002) 17-allylamino-17demethoxygeldanamycin induces the degradation of androgen receptor and HER-2/neu and inhibits the growth of prostate cancer xenografts. Clin Cancer Res 8: 986-993

55 Nielsen TO et al. (2004) Expression of the insulin-like growth factor I receptor and urokinase plasminogen activator in breast cancer is associated with poor survival: potential for intervention with 17-allylamino geldanamycin. Cancer Res 64: 286-291

56 Fumo G et al. (2004) 17-allylamino-17demethoxygeldanamycin (17-AAG) is effective in down-regulating mutated, constitutively activated KIT protein in human mast cells. Blood 103: 1078-1084

57 Munster PN et al. (2001) Modulation of Hsp90 function by ansamycins sensitizes breast cancer cells to chemotherapy-induced apoptosis in an RB- and schedule-dependent manner. Clin Cancer Res 7: 2228-2236

58 Ochel HJ and Gademann G (2005) Characterization of the combined cellular survival effects of benzoquinone-ansamycins and ionizing radiation. J Cancer Res Clin Oncol 131: 323-328

59 Heath El et al. (2005) A phase II trial of 17-allylamino17-demethoxygeldanamycin in patients with hormone-refractory metastatic prostate cancer. Clin Prostate Cancer 4: 138-141

60 Maher ER and Kaelin WG Jr (1997) von HippelLindau disease. Medicine (Baltimore) 76: 381-397

61 Ohh M and Kaelin WG Jr (2003) VHL and kidney cancer. Methods Mol Biol 222: 167-183

62 Gnarra JR et al. (1994) Mutations of the VHL tumour suppressor gene in renal carcinoma. Nat Genet 7: 85-90

63 Storkel S et al. (1997) Classification of renal cell carcinoma: Workgroup No 1. Union Internationale Contre le Cancer (UICC) and the American Joint Committee on Cancer (AJCC). Cancer 80: 987-989

64 Lubensky IA et al. (1999) Hereditary and sporadic papillary renal carcinomas with c-met mutations share a distinct morphological phenotype. $A m \mathrm{~J}$ Pathol 155: 517-526

65 Schmidt Let al. (1997) Germline and somatic mutations in the tyrosine kinase domain of the MET proto-oncogene in papillary renal carcinomas. Nat Genet 16: 68-73

66 Dharmawardana PG et al. (2004) Hereditary papillary renal carcinoma type I. Curr Mol Med 4: 855-868

67 Isaacs JS et al. (2002) Hsp90 regulates a von Hippel Lindau-independent hypoxia-inducible factor-1 alpha-degradative pathway. J Biol Chem 277: 29936-29944

68 Webb CP et al. (2000) The geldanamycins are potent inhibitors of the hepatocyte growth factor/scatter factor-met-urokinase plasminogen activator-plasmin proteolytic network. Cancer Res 60: 342-349

69 Lebret T et al. (2003) Heat shock proteins HSP27, HSP60, HSP70, and HSP90: expression in bladder carcinoma. Cancer 98: 970-977

70 Cardillo MR et al. (2000) Heat shock protein-90, IL-6 and IL-10 in bladder cancer. Anticancer Res 20: $4579-4583$

71 Yamada T et al. (2000) Function of 90-kDa heat shock protein in cellular differentiation of human embryonal carcinoma cells. In Vitro Cell Dev Biol Anim 36: $139-146$ 
72 Maruyama Tet al. (1996) Heat shock induces differentiation of human embryonal carcinoma cells into trophectoderm lineages. Exp Cell Res 224: 123-127

73 Fang $Y$ et al. (1996) Hsp90 regulates androgen receptor hormone binding affinity in vivo. J Biol Chem 271: 28697-28702

74 Minet E et al. (1999) Hypoxia-induced activation of HIF-1: role of HIF-1a-Hsp90 interaction. FEBS Lett 460: 251-256

75 Sato S et al. (2000) Modulation of Akt kinase activity by binding to Hsp90. Proc Natl Acad Sci USA 97: 10832-10837

76 Stancato LF et al. (1997) The hsp90-binding antibiotic geldanamycin decreases Raf levels and epidermal growth factor signaling without disrupting formation of signaling complexes or reducing the specific enzymatic activity of Raf kinase. J Biol Chem 272: 4013-4020
$77 \mathrm{Xu} \mathrm{W}$ et al. (2001) Sensitivity of mature ErbB2 to geldanamycin is conferred by its kinase domain and is mediated by the chaperone protein Hsp90. J Biol Chem 276: 3702-3708

78 Jerome $\mathrm{V}$ et al. (1991) Growth factors acting via tyrosine kinase receptors induce HSP90 alpha gene expression. Growth Factors 4: 317-327

79 Bagatell R and Whitesell L (2004) Altered Hsp90 function in cancer: a unique therapeutic opportunity. Mol Cancer Ther 3: 1021-1030

80 Passarino G et al. (2003) Molecular variation of human HSP90 $\alpha$ and HSP90 $\beta$ genes in Caucasians. Hum Mutat 21: 554-555

81 MacLean MJ et al. (2005) A yeast-based assay reveals a functional defect of the Q488H polymorphism in human Hsp90a. Biochem Biophys Res Comm 337: 133-137
Acknowledgments

This research was supported by the Intramural Research Program of the National Institute of Health, National Cancer Institute, Center for Cancer Research.

\section{Competing interests}

The authors declared they have no competing interests. 